\title{
DESNATURALIZANDO OS GÊNEROS: UMA ANÁLISE DOS DISCURSOS BIOLÓGICOS
}

\author{
Lilliane Miranda Freitas* \\ Silvia Nogueira Chaves**
}

RESUMO: Nesta pesquisa investigamos, em reportagens da revista Superinteressante, o processo de construção dos gêneros por meio de discursos biológicos/científicos, e a produtividade social desses discursos. Este estudo fundamenta-se nos campos teóricos de Michel Foucault e dos estudos culturais para pensar sobre a articulação saber/poder do processo de produção de gêneros divulgados nos discursos biológicos publicados pela pedagogia cultural da mídia. Nesta investigação, ficou evidenciado que os discursos biológicos predominantemente justificam e naturalizam as masculinidades e feminilidades como evidências biológicas, o que acaba por produzir e legitimar formas supostamente naturais de ser homem ou mulher e comportamentos esperados socialmente. No entanto, entendemos que os gêneros são construções sócio-históricas e culturais que nascem em relações de poder-saber, sendo as feminilidades e masculinidades não somente constituídas pelas características biológicas.

Palavras-chave: Gênero. Discurso biológico. Pedagogia cultural.

\section{DENATURALIZING THE GENDERS: AN ANALYSIS OF BIOLOGICAL DISCOURSE}

ABSTRACT: This research investigated reports in the magazine Superinteressante, how gender identity is constituted in the biological/ scientific discourse, and social productivity of these discourses. It is based on the theoretical fields of Michel Foucault and the Cultural Studies, in order to consider the connection between power/knowledge of production of gender through biological discourse published in the cultural pedagogies. In this investigation, evidence indicated that the biological discourses predominantly justify and naturalize the masculinity and femininity as biological evidence, which eventually produces and legitimizes supposedly natural ways of being male or female and socially behaviors expected. However, the genders are understood as socio-historical and cultural constructions, born from power-knowledge relationships, and where femininity and masculinity are not only constituted by biological characteristics.

Keywords: Genders, Biological discourse, Cultural pedagogies.
*Doutoranda em Educação em Ciências pela Universidade Federal do Pará (UFPA). Professora Assistente no Instituto de Estudos Costeiros da Universidade Federal do Pará (UFPA). E-mail: lilliane@ufpa.br

**Doutora em Educação pela Universidade Estadual de Campinas (UNICAMP). Professora Associada no Programa de Pós-Graduação do Instituto de Educacão Matemática e Científica da Universidade Federal do Pará. E-mail: schaves@ufpa.br 


\section{INTRODUÇÃO}

A discussão sobre os chamados sexos opostos ainda permanece bem acesa nas práticas e diferentes espaços sociais, assim como em programas televisivos, revistas, música, livros, etc. Nesse cenário, não raro verificamos a evocação de discursos científicos constituindo identidades de gênero. Muito frequentemente os argumentos partem das características biológicas dos corpos masculinos e femininos para lançar fundamentos que expliquem diferenças comportamentais, intelectuais, de habilidades e estilos de vida que supostamente distinguiriam homens e mulheres.

Entretanto, esses argumentos com base biológica não são meramente conhecimentos científicos neutros, mas descrições científicas que naturalizam características, produzindo, discursivamente, diferenças de gênero. A naturalização de identidades masculinas e femininas feita por meio de "verdades" biológicas é uma das formas pelas quais as reivindicações essencialistas podem fundamentar identidades (e desigualdades) como fixas e imutáveis (WOODWARD, 2000).

A escola privilegia as narrativas científicas como forma de contar a história da humanidade; elas ganham destaque, são hegemônicas nesse espaço, silenciando outras formas de narrar o mesmo objeto e, ao selecioná-las, o currículo institui o que é "verdadeiro". Assim, o currículo se constitui para além de um conjunto de conteúdos, objetivos, metodologias, etc, e é composto por simples seleções do repertório cultural da humanidade, que se configuram como narrativas que transmitem significados cujas funções são ensinar formas de ver e ser, ou seja, o ele envolve aquilo que somos e nos tornamos. Por isso, podemos analisá-lo levando em consideração as questões de identidade (SILVA, 1999; COSTA, 2005).

Discutir o currículo como narrativa significa romper com a trama que liga as narrativas dominantes, as formas dominantes de contar histórias, a produção de identidades e subjetividades sociais hegemônicas (SILVA, 1995; COSTA, 2005). Por isso, o currículo escolar é um lugar privilegiado dos processos de subjetivação, da socialização dirigida, controlada. Assim, as narrativas presentes em currículos contam histórias que fixam noções particulares sobre gênero, raça, classe - noções que acabam também nos fixando em posições muito particulares em torno desses eixos.

Assim, quando os gêneros são narrados, descritos cientificamente, por meio da linguagem, temos, aí, uma "realidade" biológica sendo produzida discursivamente e não apenas um relato do que é. O discurso está, portanto, instituindo a existência de masculinidades e de feminilidades e narrando como devem ser interpretadas essas características. As "coisas", os "estados de coisas" ou, nesse caso, os gêneros que se nomeiam, não são exteriores ao discurso, são precisamente objetos discursivos (LARROSA, 1994).

Por esse viés, os discursos não são, como anuncia Foucault (2008), simplesmente um entrecruzamento de coisas e palavras, tampouco os aspectos biológicos são como um conjunto de signos de uma língua. Eles são um conjunto de regras da prática discursiva, engendrada em condições que possibilitam sua 
existência; essas condições são dadas em arenas de lutas, de desigualdades; o discurso é atravessado pelo poder.

Pelo viés foucaultiano, o poder atravessa capilarmente todo o corpo social, não como uma força repressiva, negativa e centralizada, mas como produtivo, naquilo que ele é capaz de produzir em termos de efeitos, pois ele "faz", incita, induz, fabrica sujeitos. Funciona como uma rede de dispositivos, uma maquinaria social, com estratégias, técnicas, dispositivos e saberes, uma vez que nenhum poder se exerce sem a apropriação, a distribuição e a retenção de um saber. O poder é exercido pelos sujeitos e provoca efeitos sobre suas ações (FOUCAULT, 1997; 2008a).

Nesse sentido, mesmo sendo feito de signos, o discurso faz mais do que apenas designar coisas, e "é esse 'mais' que é preciso fazer aparecer e que é preciso descrever" (FOUCAULT, 2008, p. 55). O discurso define um domínio de objetos, uma "realidade", isto é, ele produz os objetos de que fala. Dessa forma, o discurso modela práticas sociais, pois toda prática social tem seu caráter discursivo, por isso "nele buscaremos antes um campo de regularidade para diversas posições de subjetividade” (FOUCAULT, 2008, p. 61).

Uma vez engendrados, os discursos científico/biológicos ganham amplitude e força ao serem veiculados pela mídia, e a circulação de tais discursos compõe vitalmente o processo de formação das masculinidades e feminilidades. Isso ocorre pelo fato de a mídia não só nos transmitir uma variedade de formas de conhecimento, dentre eles o científico, como também por produzir valores e saberes que ao serem reproduzidos naturalizam significados em relação aos gêneros.

Neste estudo, a mídia é tomada como um forte e poderoso instrumento de subjetivação pela maneira com a qual interpela, e desse modo cria, através da linguagem, modos de ser e agir no mundo, estabelecendo identidades estabilizadas. Daí veio o interesse em investigá-la. Assim, consideramos que a mídia delineia, situa, sugere e estimula determinadas formas de existência coletiva ou de relação das pessoas com elas mesmas e com os outros por meio de códigos sociais e culturais, visíveis e vividos no interior dos diferentes espaços sociais que constituem, pautam, normalizam e normatizam os gêneros (FISCHER, 2005).

Por esse viés, entendemos a mídia como um dispositivo pedagógico, chamado dentro da perspectiva dos Estudos Culturais de pedagogia cultural, uma vez que ela nos ensina alguma coisa, pois nos transmite uma variedade de formas de conhecimento que são vitais na formação da identidade e da subjetividade (SILVA, 1999). A mídia indica modos de proceder com nossas masculinidades e feminilidades e constrói verdades por meio de múltiplas estratégias; nela, o poder é organizado e difundido em relações sociais desiguais.

Por se constituírem, essas instâncias operam por meio de uma série de práticas discursivas que são tanto pedagógicas quanto políticas. Como parte de um aparato cultural mais amplo, a mídia deve ser tratada como um aparato pedagógico, formada por textos culturais ativamente envolvidos na formação de diferentes subjetividades sociais (GIROUX, 1995). Nessa perspectiva, as diferentes mídias são um lugar de aprendizado a respeito de nós e de como receberemos e leremos 
o mundo; elas nos dizem como devemos ocupar posições de sujeito particulares, o que precisamos e devemos desejar, pensar e fazer para sermos felizes, bem sucedidos (KELLNER, 1995).

Essa eficácia pedagógica para produzir comportamentos, desejos, isto é, sua performatividade, se afirmará com a incessante repetição dos discursos (SILVA, 2000). Assim, quanto mais a mídia põe em circulação os conhecimentos como simples "informações" científicas tanto mais os discursos por ela veiculados parecerão verdadeiros e se tornarão hegemônicos. Logo, essas "verdades" serão vitais na subjetivação, produzindo identidades, modelos de vida, modos de ser femininos e masculinos, de viver, de ver o mundo (ANDRADE, 2004).

Nessa direção, as revistas, como parte dos meios de comunicação de massa, também se configuram como uma potente forma de 'educar', ou seja, de conformar corpos na sociedade, na medida em que atuam como meios de formação e de informação sobre a vida, o corpo, a ciência, sobre modos de ser e viver (FISCHER, 2002). As revistas podem ser consideradas como um dispositivo pedagógico não só por serem utilizadas na escola como recurso pedagógico, mas por serem elas próprias pedagogias, ao participarem na composição da visão de mundo das pessoas, formando conceitos, que estruturam percepções, comportamentos e compreensões.

Partindo desses entendimentos, torna-se importante reconhecer o papel que as pedagogias culturais da mídia têm na moldagem de identidades sociais de gênero e analisar como as representações são construídas e assumidas, ensinadas e aprendidas, mediadas e apropriadas no contexto de formações discursivas e institucionais particulares de poder (GIROUX, 1995). Nessa direção, é pertinente, segundo Fischer (2007), ao analisar materiais midiáticos, descrever a trama estabelecida pelas complexas relações das verdades que são veiculadas e reafirmadas, a materialidade dos efeitos dessas verdades, as lutas em jogo e os modos de sujeição e subjetivação que elas produzem.

Indo nessa direção, buscamos problematizar a rede discursiva produtora de identidades naturais de gênero veiculadas pela mídia impressa. Escolhemos, então, como fontes de investigação, reportagens difundidas pela revista de divulgação científica - Superinteressante - a fim de analisar a produtividade dos discursos biológicos. Uma vez que consideramos as descrições naturais sobre mulheres e homens como fenômenos discursivos, acreditamos que o significado apreendido a respeito dessas representações é resultante não de uma essência natural, mas de um caráter discursivo.

Assim, destacamos a importância de adquirirmos uma alfabetização crítica no que diz respeito à mídia (KELLNER, 1995) a fim de aprender a questionar as representações historicamente e socialmente construídas sobre a naturalidade e as desigualdades de gênero. Isso envolve aprender as habilidades de desconstrução, de compreender como os textos culturais funcionam, como eles significam e produzem significado, como eles constituem e organizam a percepção de seus/as leitores/ as. Com isso, aprenderemos a problematizar o supostamente óbvio, aquilo que é 
tido como certo, como natural pelos discursos científicos/biológicos que nos são "vendidos" como a realidade pelas revistas científicas. Este trabalho apresenta essa necessidade de questionamento não com tom de denúncia, como se fosse possível apresentar uma perspectiva "verdadeira", mas por acreditarmos que é preciso estar atento às práticas de produção de sentido nas quais estamos envolvidos cotidianamente.

\section{PROCEDIMENTO METODOLÓGICO DE ANÁLISE DA PEDAGOGIA CULTURAL}

Ancoradas na compreensão de que a mídia atua como uma pedagogia cultural e, por isso, engendra formas de ver e ser, participando na constituição da subjetividade em relação aos gêneros, direcionamos nosso olhar para revistas de divulgação científica com o objetivo de discutir como os discursos científicos / biológicos operam na construção identitária de gêneros a partir de discursos biológicos veiculados pela divulgação científica.

Como fonte de investigação empírica, escolhemos como texto cultural e fonte de investigação a revista Superinteressante, uma publicação mensal, de circulação nacional, editada pela Editora Abril. A Superinteressante é uma publicação classificada pela própria editora como uma revista de divulgação científica; é a revista de maior tiragem no Brasil e a segunda mais antiga entre as revistas que divulgam a ciência para o grande público. Portanto, ela tem bastante impacto e representatividade como veículo midiático. Sua ampla utilização possivelmente decorre de seu perfil como revista de divulgação científica não especializada, pois possui linguagem menos formal, com muitos infográficos, esquemas, ilustrações, curiosidades. Assim, a revista é direcionada para o público em geral, e em especial o público jovem, e não para comunidades científicas. Além desses aspectos, Superinteressante é muito adotada e lida por alunos e professores em escolas por todo país, e também é frequentemente utilizada como material pedagógico na prática docente no contexto das aulas. Daí veio nosso interesse em investigá-la.

Para este estudo, o recorte que procedemos para efeito de análise compreende as edições da revista Superinteressante publicadas durante o ano de 2008, de janeiro a dezembro ${ }^{1}$, o que totaliza 13 edições, ( doze edições mensais mais uma extra - publicada no mês de dezembro). Como critério de seleção das reportagens, buscamos matérias que tratassem do objeto central dessa investigação, isto é, a instituição de identidades de gênero a partir do discurso biológico. Assim, selecionamos somente reportagens que utilizaram de algum argumento biológico, que se convencionou agrupar em conteúdos da disciplina denominada Biologia, para explicar, fundamentar ou descrever identidades, tornando-as naturais. Com base nesse critério, não privilegiamos a análise de seções específicas, examinamos todas as seções das 13 edições da revista, já que por ser uma revista que discute temáticas científicas em todas as suas seções, em todas as matérias o discurso biológico poderia estar presente. Nem mesmo os textos que são tratados com humor na revista foram dispensados de análise, porquanto mesmo no humor (e, sobretudo 
nele) há formas de representação, significação, discursos que ensinam algo e, portanto subjetivam.

Com base nesses critérios, foram selecionadas quatro reportagens que apresentavam argumentos biológicos que descreviam/fundamentavam identidades de gênero. As matérias selecionadas para análise, e suas respectivas seções, foram: "Quem é menos burro?", capa (edição 256. set. 2008); “Ansiedade”, capa (edição 258. nov. 2008); "E se não houvesse a monogamia?", Srespostas (edição 260. dez. 2008); e“Engordar pecar sofrer", comportamento (edição 256. set. 2008).

A partir das reportagens selecionadas para análise, buscamos discutir a naturalização dos gêneros fabricada em relações de poder presentes em discursos científicos, como por exemplo, nos discursos sobre evolução, genética, neurociências, bioquímica, anatomia, fisiologia, dentre outros, utilizados por cientistas e jornalistas na revista de forma supostamente isenta de forças sociais, culturais, políticas, econômicas, tomados como meras descrições, explicações, conhecimento.

Dessa forma, procuramos problematizar o caráter contingente dos discursos biológicos como conhecimentos produzidos em instâncias, instituições e processos culturais que estão, como qualquer outro discurso, conectados em intrincadas relações de poder. Analisamos também os possíveis efeitos sociais que a pretensa neutralidade com que circulam na rede discursiva biológica pode produzir ao ensinar, explicar, informar e, como uma pedagogia cultural, pode também subjetivar, impondo-nos modos de ver e estar no mundo como homens e mulheres.

Consideramos que o ponto importante não é definir qual a verdade formulada pelos discursos biológicos presente nessas reportagens, nem mesmo revelar possíveis mentiras que estariam aí ocultadas. Não nos preocupa saber se os discursos estão "provados cientificamente", ou seja, se as matérias são realmente "verdadeiras", se estão de acordo com a (múltipla e contraditória) visão da comunidade científica (pois nem mesmo se trata de uma revista de divulgação científica especializada). Nosso objetivo é conhecer "a vontade de saber que lhe serve ao mesmo tempo de suporte e instrumento" (FOUCAULT, 2009, p. 18). Nessa perspectiva, vale ressaltar que não pretendemos denunciar uma possível falsa visão de ciência, ou um mau uso dela, nem julgar a revista Superinteressante como sendo ou não "verdadeiramente" científica, através de uma análise maniqueísta.

Assim, nossa preocupação não é com a "verdade" científica, mas analisar a força que esses discursos, proposições biológicas, possuem por encontraremse "no verdadeiro", por formarem a complexa grade da ordem do discurso, na qual "não se tem o direito de dizer tudo, que não se pode falar de tudo em qualquer circunstância, que qualquer um enfim não pode falar de qualquer coisa" (FOUCAULT, 2009a, p. 9). Dessa forma, consideramos importante analisar esses discursos que não são interditados, mas são selecionados, organizados, distribuídos, propagados por procedimentos e técnicas que têm por função tornar possível seu surgimento, seus efeitos, sua materialidade. 


\title{
ANALISANDO A NATURALIZAC̣̃̃O DOS GÊNEROS NA PEDAGOGIA CULTURAL
}

A primeira matéria que analisamos, intitulada "Quem é menos burro?”, discute a polêmica em relação à diferença do tamanho e do desempenho da inteligência de homens e mulheres. Nela, destacamos os seguintes excertos:

Quem é menos burro? Não interessa se você é homem ou mulher: o sexo não diz nada sobre o tamanho da sua inteligência. Mas nem por isso os dois têm cérebros iguais. Veja como essas diferenças podem influenciar nas escolbas mais importantes de sua vida. E dizer quem vocêe é (“Quem é menos burro?”, set/2008 p. 68, grifos nossos).

\begin{abstract}
Esse episódio de Os Simpsons brinca com aquela polêmica de 2005, quando o então reitor da Universidade Harvard, Lawrence Summers, disse que havia explicações biológicas para of fato de haver poucas mulberes na elite cientifica. Mas até que ponto Summers falou besteira? Tudo começa com um fato: quando o assunto é aptidão para ciências exatas, as diferenças estatísticas são claras. Mais de 70\% dos estudantes de engenharia no Brasil são homens, enquanto as mulheres dominam as ciências humanas. (...) Começando pela biologia. O que não faltam são evidências de algo que você já sabe: as mulheres entendem melhor de pessoas; os homens, de coisas. (...) Estudos recentes mostram que essas características se manifestam desde os primeiros momentos da vida, o que põe em xeque a teoria de que esse tipo de comportamento é resultado apenas da sociedade (...) Então é natural que os homens tendam a escolher carreiras em que essa capacidade faz a diferença. (...) Como a habilidade de lidar com pessoas tem mais a ver com o cérebro feminino, elas em geral se sentem mais atraídas por carreiras que vão lidar com gente ou com sentimentos ("Quem é menos burro?", set/2008 p. 68-70, grifos nossos).
\end{abstract}

Muito embora o subtítulo já contenha a afirmação de que "o sexo não diz nada sobre o tamanho da sua inteligência", uma série de argumentos inatistas comparece de modo a caracterizar, se não o grau, o tipo de inteligência "próprio" do universo masculino ou feminino, como se fossem aspectos inatos a cada gênero, inalienáveis a tal ponto que seria possível antever tendências, aptidões, escolhas.

No entanto, consideramos que as identidades de gênero e as diferenças instituídas não são entidades inatas, preexistentes, que existem desde sempre ou que passaram a existir a partir de algum momento fundador; elas não são elementos inertes em relação à cultura, mas são constantemente criadas e recriadas em uma produção que envolve o cruzamento de diferentes elementos, como os discursos políticos e culturais e as histórias particulares (SILVA, 2000).

Nessa matéria, a base para os argumentos que supostamente justificam a supremacia masculina na ciência são "explicações biológicas", como evidencia o reitor de Harvard. A justificativa biológica vem outra vez ancorada em noções essencialistas, uma vez que as diferenças que determinam as escolhas profissionais de homens e mulheres e as próprias diferenças entre os gêneros supostamente "se manifestam desde os primeiros momentos da vida".

Não é de hoje que há esforços científicos para produzir "evidências" que diferenciem homens e mulheres, por meio da anatomia, fisiologia, genética, neurociências e de toda uma parafernália científica, para estabelecer dicotomias, 
polarizações e desigualdades entre os gêneros, a fim de verificar quem é mais isso, ou menos aquilo, como no título da matéria: "Quem é menos burro?". No entanto, as diferenças sexuais que a ciência busca descrever não são simplesmente marcadas em função de diferenças materiais que não sejam, de alguma forma, simultaneamente marcadas e formadas por práticas discursivas (BUTTLER, 2000). Assim, é por meio da marcação da diferença que as identidades são fabricadas. Entretanto, algumas diferenças entre mulheres e homens são vistas como mais importantes que outras, especialmente em lugares particulares e em momentos particulares. E como toda prática discursiva, está imersa em relações de poder:

Se a sexualidade se constitui um domínio a conhecer, foi a partir de relações de poder que a instituíram como objeto possível; e em troca, se o poder pode tomá-la como alvo, foi por que se tornou possível investir sobre ela através de técnicas de saber e de procedimentos discursivos (FOUCAULT, 2009, p. 108-109).

A matéria sob análise, ao tratar como evidência biológica diferenças entre os gêneros, acaba por produzir e legitimar formas supostamente naturais de ser homem ou mulher. Tal naturalidade se traduz em comportamentos, atitudes, "aptidões, habilidades" esperadas e desejadas, para esse ou aquele gênero, desde "os primeiros momentos de vida". Naturalizadas, as "explicações biológicas" produzem discursos nos quais as diferenças são tão óbvias, indubitáveis, que até "você (leitor) já sabe", porque "não faltam evidências" para comprová-las.

Nessa direção, os destinos sociais dos gêneros já estão dados a priori. Homens e mulheres, enquadrados em seus respectivos atributos, seguem (ou pelo menos deveriam seguir) suas vocações obedecendo ao grande plano traçado em seus aparatos biológicos. Por esse viés, nem cultura, nem história ou sociedade, tomam parte na formação dos gêneros. Ao contrário, a ciência "põe em xeque a teoria de que esse tipo de comportamento é resultado apenas da sociedade".

Entretanto, as relações sociais não são resultado apenas de um reflexo biológico, uma vez que lidamos com um homem/mulher naturalmente homem/ mulher. Agir socialmente como mulher ou homem implica estar envolvido na força da mediação cultural, pois toda prática social tem uma dimensão cultural. As práticas sociais dependem e têm relação com o significado que é dado culturalmente, ou seja, a cultura é uma das condições constitutivas de existência do agir e decidir (HALL, 1997). Nessa perspectiva, os códigos sociais não estão no indivíduo feminino ou masculino, não nascem impressos nele, como referidos na reportagem, desde "os primeiros momentos de vida", mas já estão dados culturalmente:

Os códigos fundamentais de uma cultura - aqueles que regem sua linguagem, seus esquemas perceptivos, suas trocas, suas técnicas, seus valores, a hierarquia de suas práticas - fixam logo de entrada, para cada homem, as ordens empíricas com as quais terá de lidar e nas quais se há de encontrar (FOUCAULT, 1999, p. xvi). 
Dessa forma, as ações individuais de mulheres e homens são menos biológicas do que são sociais e históricas, pois os indivíduos agem no mundo em condições sócio-históricas particulares que estão refletidas em seus projetos políticos e nas relações de poder nas quais operam (MOITA-LOPES, 2002).

Ainda é interessante destacar as palavras escolhidas para referir uma e outra explicação para diferenças entre gêneros. Do lado biológico temos evidências, do lado societário temos teorias. Não importa aqui provar qual dessas teorias é a que mais se aproxima da verdade, visto que entendemos ser a própria verdade um efeito de poder (FOUCAULT, 2008a). Importa interrogar a produtividade desses discursos - "que efeitos recíprocos de saber e poder proporcionam"? (FOUCAULT, 2009, p. 113) - ao opor ciência e sociedade, como dimensões independentes, elipsando os jogos de poder implicados nas diferenciações entre gêneros.

A própria matéria já traz alguns dos efeitos produzidos por esse discurso ao indicar que há "poucas mulheres na elite cientifica" e, ainda, que "mais de 70\% dos estudantes de engenharia no Brasil são homens". Contudo, os efeitos aparecem como consequências, desdobramentos esperados de uma identidade que já nasce pronta. Vemos, nessas estatísticas, a produção, a materialização do objeto de que fala a ciência. Porquanto, se naturalmente "as mulheres entendem melhor de pessoas; os homens, de coisas", ambos estão convocados a se enquadrarem nessa condição, realizando sua destinação de homens e mulheres normais.

Aí reside a eficácia produtiva dos discursos; sua repetida pronunciação acaba fabricando aquilo de que fala e que, supostamente, apenas descreve. Esse é o caráter "performativo" do discurso: fazer com que ele aconteça (SILVA, 2000, p. 93). Dessa forma, tudo o que se diz repetidamente, em uma sociedade, sobre como devem ser os gêneros, vai construindo a materialidade dessas identidades. Assim, as práticas discursivas exercem seus efeitos para além do próprio discurso, ela nos liga aos elementos que estão a ele articulados (FOUCAULT, 2008).

Nessa perspectiva, a produção de identidades de gêneros biologicamente "normais" forja preferências, interesses, em desenvolver determinadas habilidades ou saberes compatíveis com referências socialmente admitidas para masculinidade e feminilidade. O normal é tomado, então, como critério normativo de julgamento, que julga e que valoriza a diferença (LARROSA, 1994). Normalizar seria eleger arbitrariamente uma identidade específica como padrão, nesse caso, de homens e mulheres padrão, em relação às características por meio das quais todas as outras identidades serão avaliadas e hierarquizadas. Assim, os critérios que distinguirão a normalidade dos gêneros, como também a anormalidade, estarão inscritos em sistemas de referência científica, sistematizados em disciplinas, teorias, leis e especificidades (FOUCAULT, 1997).

A corrida para se tornarem homens ou mulheres "de verdade", para alcançarem objetivos e trilharem percursos esperados para o gênero, leva, por exemplo, homens e mulheres a desenvolverem atividades que lhes desagradam, que lhes trazem desconforto ou não lhes satisfazem, só para atenderem às exigências sociais que os posicionam em atributos que seriam "naturalmente" características de seu gênero (LOURO, 2000). 
Por outro lado, desenvolver bem uma atividade ou prática que não é "típica" de um determinado gênero, como, a exemplo da matéria, se mulheres mostrassem "aptidão para ciências exatas", certamente isso não seria reconhecido como uma "aptidão", palavra que remete à capacidade, disposição inata do indivíduo. Segundo Louro (2000), o bom desempenho de mulheres em Matemática está frequentemente relacionado ao esforço, trabalho árduo, e nunca ao brilhantismo ou potencialidade, adjetivos que são utilizados para definir os homens que são bem sucedidos nessa área. Há uma expectativa criada de que as meninas naturalmente fracassem e que os meninos sejam bem sucedidos em ciências exatas, e que em relação às ciências humanas ocorra o inverso, pois, segundo a ciência, "a habilidade de lidar com pessoas tem mais a ver com o cérebro feminino".

Há de se notar que os indivíduos que fogem às normas e não atingem às expectativas esperadas, e não obedecem à lógica dicotômica dos gêneros, adquirem o rótulo de desviantes, problemáticos e patológicos. Outro efeito é o silenciamento ou banimento social de grupos que não se enquadram na polarização imposta (LOURO, 2000), como é o caso de homossexuais e transgêneros. Nas comparações classificatórias são chamados anormais aqueles cuja diferença em relação à maioria se convencionou classificar como intolerável, incômodo, exagerado, fora do permitido, oposto ao normal. Assim, a anormalidade passa a ser considerada um desvio, algo indesejável, porque a norma não admite exterior, já que os princípios de formação de um saber e um poder de normalização são mecanismos com os quais se pretende "defender a sociedade" de qualquer "degenerescência” (FOUCAULT, 1997, p. 66).

Por esses entendimentos, há uma conduta social que, ao ser seguida, produzirá as masculinidades e feminilidades supostamente normais, esperadas para aquela sociedade. Sobre essa produção de perfis de gênero, destacamos a seguinte matéria:

\begin{abstract}
Há outro ponto gerador de ansiedade: ser mulher. Elas costumam sofrer mais com transtornos de ansiedade do que os homens por dois motivos. O primeiro é hormonal: "A mulher não produz hormônios regularmente como o homem. No periodo pré-menstrual, por exemplo, o cérebro dela fica privado de duas substâncias calmantes e antidepressivas, que são o estrógeno e a progesterona. Essa produção inconstante causa a TPM e a deixa mais vulnerável aos transtornos ansiosos", diz Valentim Gentil, professor da USP e Ph.D. em psiquiatria pela Universidade de Londres. O segundo é social: para as mulheres, é natural expressar os sentimentos, e elas são treinadas desde pequenas para externar sensações normalmente. Já o homem aprende que sentir ansiedade é sinal de fraqueza, e tem que lidar com ela para ser mais bem aceito socialmente ("Ansiedade", nov/2008, p. 70 , grifo nosso).
\end{abstract}

Esse argumento biológico traz a ideia de que há uma entidade feminina, um "ser mulher". Entretanto, de acordo com a perspectiva adotada neste estudo, ser homem e ser mulher constituem-se em processos que acontecem em âmbito cultural, social e histórico, assim, os elementos biológicos não formam a base das identidades de gênero (LOURO, 2008). Entendidos dessa forma, os gêneros não se definem exclusivamente por características biológicas, sexuais, construídas por 
meio de discursos biológicos, pois não há nada de essencial em ser homem ou ser mulher (HARAWAY, 2000).

Outra vez, não se trata de negar a materialidade dos corpos, de negar, por exemplo, a ocorrência dos ciclos fisiológicos e suas ações de regulação hormonal. A materialidade existe, ela não é negada, porém, o que é colocado em suspeição são as descrições, as interpretações e as narrações que são feitas de um dado objeto. O "próprio mundo vivo", tal como nos diz Haraway (1992), existe independente das nomeações e classificações biológicas em categorias, ou seja, as coisas existem em sua materialidade, entretanto, não há fronteiras, categorias dadas, $a$ priori, que possam ser apenas descritas ao olhá-las, as criaturas são tanto naturais quanto fabricadas. É para esse pressuposto que Willinsky (2004, p. 112) nos alerta quando indaga: "Onde, precisamente, residiria a noção de subespécie - nos olhos do observador ou nas próprias criaturas?”. Sobre isso, Foucault argumenta:

\footnotetext{
Não basta abrir os olhos, prestar atenção, ou tomar consciência, para que novos objetos se iluminem e, na superfície do solo, lancem sua primeira claridade (...). O objeto não vai esperar nos limbos a ordem que vai liberá-lo e permitir-lhe que se encarne em uma visível e loquaz objetividade; ele não preexiste a si mesmo, retido por algum obstáculo aos primeiros contatos da luz, mas existe sob as condições positivas de um feixe complexo de relações (FOUCAULT, 2008, p. 50).
}

Desta forma, importa assumir que é no interior da cultura, e de uma cultura específica, que essas características materiais, neste caso, características biológicas sexuais, adquirem significados, e é preciso desconfiar desses significados atribuídos aos gêneros, como o de que as mulheres "costumam sofrer mais com transtornos de ansiedade do que os homens", já que a natureza em si mesma é - culturalmente falando - silenciosa (SILVA, 2000).

Ainda nesse fragmento da matéria, percebemos a ambivalência dos discursos sobre como masculinidade e feminilidade, que vão sendo engendradas pelo discurso biológico (interferência hormonal) e pelo social. Há alguns aspectos comportamentais admitidos, na matéria, pelo cientista, como condições socialmente aprendidas, por exemplo, a expressão de sentimentos pela mulher de forma " $n a$ tural' ou a aprendizagem da virilidade nos homens, o ser másculo, durão, forte, o ocultamento de qualquer "sinal de fraqueza" condição que socialmente não se relaciona com o universo masculino, pelo menos não o do verdadeiro homem que pretende ser "bem aceito socialmente". Muito embora o cientista se refira aos aspectos sociais e até problematize a condição aprendida deles, o aspecto hormonal, biológico, comparece como um fator essencial e determinante para o "ser mulher", sendo inclusive destacado em primeiro lugar, como o "primeiro ponto gerador" antes mesmo do social, isto é, o aspecto social continua em segundo plano, como complemento ou mesmo desdobramento do aparato biológico.

Pelo viés social, as mulheres "são treinadas desde pequenas", não só a expressar sentimentos - mas também a admirar, simpatizar com determinado tipo de 
atitudes, objetos, cores, antes mesmo de nascerem. Por que será que as meninas gostam mais da cor rosa do que os meninos? Por que preferem bonecas a carrinhos? No universo das crianças essas diferenças vão sendo produzidas desde o momento em que as famílias são informadas do sexo do bebê e passam a organizar a paisagem ambiental (as cores, os enfeites do quarto, os brinquedos) em que esse novo membro do grupo social será recebido; a projetar seu futuro, a delimitar o que deve ser valorizado ou desvalorizado, o que pensar, como se comportar, o jeito certo de falar, andar, vestir, etc., tudo para "ser mais bem aceito socialmente". Esses são, em seu conjunto, os elementos que fabricarão masculinidades e feminilidades em cada sociedade.

As práticas discursivas que produzem condutas sociais se constituem em uma espécie de ritual superficial e visível (FOUCAULT, 2009a) que impõe aos indivíduos certo número de regras, e que determina que cumpram certas exigências:

\begin{abstract}
Define os gestos, os comportamentos, as circunstâncias, e todo o conjunto de signos que devem acompanhar o discurso; fixa, enfim, a eficácia suposta ou imposta das palavras, seu efeito sobre aqueles aos quais se dirigem, os limites de seu valor de coerção (...) um ritual que determina para os sujeitos que falam, ao mesmo tempo, propriedade singulares e papéis preestabelecidos (FOUCAULT, 2009a, p. 39).
\end{abstract}

Nesse sentido, compreendemos que há um conjunto de signos que acompanham o ritual de transformar-se em homem e mulher que vão sendo dados nas falas, nos gestos, nos modos de ser e agir que constituirão a normalidade das identidades de gênero. Porém, a norma não emana de um único lugar, mas, em vez disso, está em toda parte. Ela se expressa por meio de recomendações repetidas e observadas, cotidianamente, que vão "treinando" condutas para adquirirem um status de normalidade que sirvam de referência a todos. Isso explica o motivo pelo qual a norma se faz penetrante e por que ela é capaz de se naturalizar (LOURO, 2008a). Portanto, antes de simplesmente assumir noções dadas de normalidade e de diferença, parece produtivo pensar sobre os processos de inscrição dessas marcas. A diferença é ensinada, marcada em relações desiguais de poder, e possui sua utilidade.

Assim, os gêneros se produzem nas e pelas relações de poder. Homens e mulheres se fazem por meio de práticas e relações que instituem condutas e posturas apropriadas, como por exemplo, o fato de o homem não "sentir ansiedade", ou ter que gostar de futebol, o que para aqueles tidos como normais e sadios é considerado quase uma obrigação (LOURO, 2008).

Porém, as condutas masculinas e femininas são naturalizadas pela ciência como uma "razão biológica", e que por serem supostamente biológicas, naturais, seus efeitos tenderiam a ser mais toleráveis socialmente. Sobre isso, destaco a matéria "E se não houvesse a monogamia?", que trata sobre as consequências sociais da possibilidade de um regime poligâmico e as causas biológicas que autenticam o sistema monogâmico: 
'Casais' formados por uma mulher e vários maridos praticamente nunca existiriam. A razão ai é biológica. Se vários homens casam com a Angelina Jolie, nenbum vai saber com certeza se épai de algum dos filhos que saírem dela. Isso moldou o cérebro masculino para ter asco à ideia de dividir uma parceira. E atépara matar rivais se for necessário. As mulheres? Elas também sentem ciúmes, lógico, mas não de uma forma tão intensa. Se dez moças casarem com Brad Pitt, todo mundo na casa vai saber quem é o pai e a mãe de cada criança. Isso ameniza bem as coisas e torna essa 'vida a 11' mais ou menos tolerável ("E se não howvesse a monogamia?", dez/2008, p. 57, grifos nossos).

Ao longo da história, as mulheres conviveram melhor com a ideia de dividir um cônjuge do que os homens ("E se não houvesse a monogamia?", dez/2008, p. 56, grifo nosso).

Nesses excertos, as explicações científicas operam na instituição de posições e condutas sociais, e na distribuição e circulação desses atributos incorporados por homens e mulheres. Aos homens, é dado direito "até para matar rivais se for necessário" para garantir a exclusividade sexual da parceira e certeza de paternidade sobre os filhos, pois a paternidade, segundo a matéria, de certa forma "moldon o cérebro masculino para ter asco à ideia de dividir uma parceira”. Porém, quando se refere às mulheres, não é dada tanta ênfase à repulsa que a não exclusividade do parceiro poderia causar, porque elas não sentiriam o ciúme "de uma forma tão intensa" quanto os homens, o que permitiria que fosse bem mais ameno e "mais ou menos tolerável" uma situação de poligamia masculina . Assim, institui-se a ideia de que "as mulheres conviveram melhor com a ideia de dividir um cônjuge do que os homens".

Temos aí um discurso de "cérebros moldados" e uma elipse dos processos culturais de fabricação das pessoas, naturalizando, instituindo e sancionando condutas desiguais. Discursos desse tipo já justificaram (e ainda hoje justificam), no âmbito jurídico, inúmeros episódios de violência contra as mulheres, constituindo-se muitas vezes argumentos legais para absolvição de réus que nada mais fizeram do que preservar sua 'honra' ao cometerem barbarismos por "não conviverem bem" ou por "não tolerarem a ideia de dividirem suas parceiras".

Homens e mulheres são submetidos a processos de socialização sexual nos quais noções culturalmente específicas de masculinidade e feminilidade são fabricadas ao longo da vida. É por esse processo de socialização sexual que os indivíduos aprendem os desejos, sentimentos, atributos, condutas e práticas sexuais esperados de seus grupos de idade ou de status dentro da sociedade, bem como as alternativas sexuais que suas culturas lhes possibilitam (PARKER, 2000).

No entanto, na matéria, observamos que as atitudes violentas, agressivas, impetuosas, dos homens, parece se justificar por um discurso neurocientífico de adaptação "ao longo da história" do "cérebro masculino para ter asco à ideia de dividir uma parceira"; e considerando que seria difícil ir "contra a natureza", a própria biologia garante que situações como a poligamia feminina "nunca existiriam", e mesmo se viessem a existir, seriam supostamente antinaturais. Já a conduta biológica das mulheres é descrita como não intensa, amena, isto é, fraca, branda e frágil, reforçando o discurso de fragilidade da mulher, que segundo Foucault (2008, p. 234), 
é há muito tempo descrita como "frágil"; essa característica natural da mulher a tornaria tolerante, pacífica, dócil, facilmente controlável.

Nessas descrições, nada neutras, percebemos que os padrões de feminilidade são, como anuncia Weeks (2000), inescapavelmente, um produto do poder dos homens para definir o que é necessário e desejável para eles e para elas - um poder desigual historicamente enraizado. Assim, consideramos que o gênero não se constitui como uma simples categoria analítica, biológica, mas como uma relação tácita de poder que se sustenta em um saber que tem vontade de verdade sobre os gêneros:

O que está em jogo, senão o desejo e o poder? O discurso verdadeiro, que a necessidade de sua forma liberta do desejo e libera do poder, não pode reconhecer a vontade de verdade que o atravessa; e a vontade de verdade, essa que se impõe a nós há bastante tempo, é tal que a verdade que ela quer não pode deixar de mascará-la (FOUCAULT, 2009a, p. 20).

Ainda com relação aos modos supostamente normais de comportar-se sexualmente, a matéria "Engordar pecar sofrer" aponta dados numéricos e em gráficos do IBGE (Instituto Brasileiro de Geografia e Estatística) de pesquisas feitas no Brasil e também nos EUA, sobre a relação entre a idade das mulheres, o casamento e a maternidade. Esses dados apontam que:

De acordo com o IBGE, mais de 60\% das brasileiras entre 20 e 29 anos com ensino superior não são casadas (...). Ai começa uma corrida contra o relogio. Biologicamente falando, 30 anos é a idade chave para engravidar. A partir dai, os óvulos começam a envelhecer e a gravidez torna-se mais difícil e mais complicada. Dos 18 aos 40 anos, a chance de um óvulo ser fecundado cai de 30\% para 5\%. Isso explica o aumento pela procura das clínicas de fertilidade nos últimos 20 anos. "O ideal é que as mulheres não deixem para ter filhos muito depois dos 30 anos, se elas estiverem no mercado de trabalho, precisam cavar espaco para a maternidade", diz Roger Abdelmassih, médico especialista em fertilidade ("Engordar pecar sofrer", set/2008, p. 91, grifos nossos).

Essa reportagem, "Engordar pecar sofrer", trata do que ela nomeia de "crise dos 30 anos". São usados argumentos biológicos e sociais para explicar essa crise, que é desencadeada, segundo a reportagem, pelo envelhecimento do corpo e pelo insucesso do alcance de metas esperadas para as mulheres que estão nessa idade, que se resumem em: casamento, filhos e profissão.

Nesse controle estatístico, há um saber político que tem como preocupação a vida privada dos indivíduos, principalmente na sua idade produtiva economicamente. Esse controle seria parte dos mecanismos que asseguram a regulação disciplinar analisada por Foucault. Trata-se do exercício de uma vigilância sobre o corpo do indivíduo a fim de controlá-lo. A vigilância faz parte das técnicas que Foucault (2008a) chama de disciplina:

Uma técnica de poder que implica uma vigilância perpétua e constante dos indivíduos. Não basta olhá-los às vezes ou ver se o que fizeram é conforme a regra. É preciso vigiá-los durante todo o tempo da atividade e submetê-los a uma perpétua pirâmide de 
olhares (...). A disciplina é o conjunto de técnicas pelas quais os sistemas de poder vão ter por alvo e resultado os indivíduos em sua singularidade. E o poder de individualização que tem o exame como instrumento fundamental. O exame é a vigilância permanente, classificatória, que permite distribuir os indivíduos, julgá-los, medi-los, localizá-los e, por conseguinte, utilizá-los ao máximo. Através do exame, a individualidade torna-se um elemento pertinente para o exercício do poder (FOUCAULT, 2008a, p. 106-107).

Dessa forma, a vigilância tem como meta o controle das atitudes e comportamentos do indivíduo. Seu principal objetivo é imprimir no indivíduo vigiado a própria visão de quem o olha, de quem o vigia, de tal modo que o sujeito seja capaz de controlar-se a si mesmo sem ser, para isso, vigiado.

Percebemos esse efeito, e a própria materialização do discurso, nos dados que a reportagem anuncia, sobre o "aumento pela procura das clínicas de fertilidade nos últimos 20 anos" devido à cobrança social de que "o ideal é que as mulheres não deixem para ter filhos muito depois dos 30 anos". Por esse viés, percebemos que há, por parte das próprias pessoas, uma cobrança, que também é social, pelo alcance dessas metas traçadas para a mulher nessa determinada idade. Segundo essa ideia, é preciso que ela se enquadre dentro da normalidade esperada, dentro do "ideal", para que não seja vista como fracassada, infeliz, frustrada e "encalhada", o que pode desencadear "crises" como a que é destacada pela reportagem "Engordar pecar sofrer".

Percebemos que esse aspecto, da fecundidade e do relacionamento matrimonial, é cobrado especialmente das mulheres, de forma que o censo do IBGE é feito com elas; não aparece na reportagem a mesma estatística para os homens, com que idade casam, a idade ideal para ter filhos, a relação escolaridade-casamento. Isso porque delas espera-se, como medida de sucesso, um "bom casamento e filhos", e dentro de uma idade específica para isso. Assim, a mulher estaria obedecendo ao seu instinto natural, pois "biologicamente falando, 30 anos é a idade chave para engravidar". Além disso, segundo a convenção social, espera-se que a "mulher direita" engravide dentro do casamento. Não é à toa que há, em nossa sociedade, muitas medidas para suprir (ou pelo menos tentar) essa suposta falta/desvio/anormalidade relacionada ao não casamento delas, como os prolíferos sites de relacionamento e, especialmente, a chamada fábrica de casamentos, que consistem em empresas especializadas em promover relacionamentos com vistas ao casamento; e quanto aos filhos, "pela procura das clínicas de fertilidade", fazendo movimentar toda uma indústria de fertilidade sustentada por laboratórios, clínicas, médicos, biomédicos, etc.

Assim, cada cultura delimita formas de "regular culturalmente" as condutas por meio dos sistemas classificatórios; eles definem os limites entre a semelhança e a diferença, o que é aceitável e o que é inaceitável em relação ao comportamento, às roupas, o que pode ser dito, os hábitos e que costumes e práticas são considerados como "ideais" para os gêneros. Classificar ações e comparar condutas e práticas humanas de acordo com nossos sistemas de classificação cultural é, assim, mais uma forma de regulação cultural (HALL, 1997).

Muito embora haja uma corrida para a fixação, a homogeneização, há também, na contramão, a existência de variações culturais que contradizem as 
noções de atributos universais de gênero, o que não deixa de ser um aspecto da subjetivação e da produção da identidade, os processos de estabilização e subversão (SILVA, 2000). Isso porque o discurso pode ser, concomitantemente, "instrumento e efeito de poder, e também obstáculo, escora, ponto de resistência e ponto de partida de uma estratégia oposta. O discurso veicula e produz poder" (FOUCAULT, 2009, p. 112).

Isso significa que ser macho ou fêmea, masculino ou feminino, em contextos sociais e culturais diferentes, pode variar enormemente, e a identidade de gênero não é claramente redutível a qualquer dicotomia biológica subjacente (PARKER, 2000). Os gêneros se inscrevem em subjetividades que possuem caráter fragmentado, instável, histórico e plural, é contingente. Por isso, não há sentido em se buscar uma matriz identitária natural para os gêneros, pois nenhuma construção identitária é totalitária, verdadeira (LOURO, 2000; HARAWAY, 2000).

\section{CONCLUSÕES}

Ao tomarmos o discurso biológico/científico e outros discursos como construções sociais, históricas e culturais, consideramos que importa desconfiar daquilo que é tomado como natural, das práticas rotineiras e comuns, dos gestos e das palavras banalizados que inscrevem as identidades de gênero. É necessário, ainda, desestabilizarmos essas verdades, tomá-las como alvos de atenção, questionar os discursos biológicos que frequentam a mídia, os bate-papos informais e as salas de aula, que naturalizam e marcam feminilidades e masculinidades, também, no cotidiano escolar.

Nesse sentido, o campo da educação também se mostra regulado por classificações, presentes no currículo, que nos permitem nomear as diferenças de gênero, conferindo-lhes significados. Consideramos currículo como um conjunto de narrativas, estabelecido em arenas de luta, que ensina formas de ver e ser, produzindo subjetividades; tal noção implica na compreensão de que outras instâncias culturais, para além da escola, também subjetivam, portanto, possuem seus próprios currículos, ensinam, consistindo, assim, pedagogias culturais.

No entanto, somos inclinados, geralmente, a esquecer o quanto essas classificações, significados, categorias, conceitos, nomes, taxonomias, ampliam ou reduzem aquilo que podemos pensar, sentir, dizer, fazer. Deixamos que elas constituam o campo do possível, nos permitindo certas coisas e não outras, nos ensinando a ver e a nos comportar de determinadas formas, enfim, constituindo nossos modos de ser femininos e masculinos. Diante desses entendimentos, compreender, identificar e questionar os regimes de regulação inscritos no currículo escolar, isto é, na maneira como este fabrica subjetividades, significa abrir a possibilidade para além de contestar e modificar aquelas relações de poder que tendem a estigmatizar, inferiorizar e excluir certos saberes e grupos sociais e, também, compreender os processos de fabricação identitárias de gênero. 
Nesse jogo de desestabilização das identidades de gênero, suspeita e recusa, o papel do professor é central, pois importa que a prática pedagógica seja uma prática política, comprometida em criar espaços para transformação, subversão, interferência, resistência e recusa das formas fixas de fabricação de feminilidades e masculinidades. Assim, destacamos também a importância de adquirirmos uma alfabetização crítica da mídia (KELLNER, 1995) e passar a questionar aquelas representações historicamente e socialmente construídas. Isso envolve aprender as habilidades de desconstrução, de compreender como os textos culturais funcionam, como eles significam e produzem significado, como eles constituem e organizam a percepção, neste caso, moral, de seus/as leitores/as.

\section{NOTA}

${ }^{1}$ Optamos pela edição de 2008 por ser ela a mais recente e completa (todos os números já estavam circulando) em relação ao ano em que iniciamos esta pesquisa, 2009.

\section{REFERÊNCIAS:}

ANDRADE, S. S. Mídia, corpo e educação: a ditadura do corpo perfeito. In: MEYER, D. E; SOARES, R. F. R (orgs.). Corpo, Gênero e Sexualidade. Porto Alegre: Editora Mediação. 2004.

BUTLER, J. Corpos que pesam: sobre os limites discursivos do sexo. In: LOURO, G. L (org). O corpo educado: pedagogias da sexualidade. Belo Horizonte: Autêntica. 2000.

COSTA, M. V. Currículo e Política Cultural. COSTA, M. V.(org.) O currículo nos limiares do contemporâneo. Rio de Janeiro: DP\&A, 2005.

FISCHER, R. M. B. Uma análise foucaultiana da TV: das estratégias de subjetivação na cultura. Curriculo sem Fronteiras, v. 2, n. 1, p. 41-54, 2002.

FISCHER, R. M. B. Mídia e juventude: experiências do público e do privado na cultura. Cad. Cedes, Campinas, vol. 25, n. 65, p. 43-58. 2005.

FISCHER, R. M. B. Mídia, máquinas de imagens e práticas pedagógicas. Revista Brasileira de Educação, Rio de Janeiro,v. 12 n. 35, p.290-299, 2007.

FOUCAULT, M. Resumo dos Cursos do Collège de France (1970-1982). Rio de Janeiro: Jorge Zahar. 1997. FOUCAULT, M. As palavras e as coisas: uma arqueologia das ciências humanas. São Paulo: Martins Fontes. 1999.

FOUCAULT, M. A arqueologia do saber. Rio de Janeiro: Forense Universitária. 2008.

FOUCAULT, M. Microfisisica do Poder. Rio de Janeiro: Edições Graal. 2008a.

FOUCAULT, M. História da Sexualidade I: a vontade de saber. 19 ed. Rio de Janeiro: Edições Graal. 2009. FOUCAUlT, M. $A$ ordem do discurso: aula inaugural no Collège de France, pronunciada em 2 de dezembro de 1970. São Paulo: Edições Loyola. 2009a.

GIROUX, H. A. Memória e pedagogia no maravilhoso mundo da Disney. In: SILVA, T. T. Alienígenas na sala de aula. Rio de Janeiro: Vozes. 1995.

HALL, S. A centralidade da cultura: notas sobre as revoluções culturais do nosso tempo. Educaşão \& Realidade. Porto Alegre, v. 22, no 2, p. 15-46. 1997.

HARAWAY, D. The promises of Monsters: a regenerative politics for inappropriate/d others. IN: GROSSBERG, L; NELSON, C; TREICHLER, P. (orgs.) Cultural Studies. New York/London: Routledge. 1992. 
HARAWAY, D. Manifesto ciborgue: ciência, tecnologia e feminismo-socialista no final do século XX. In: SILVA, T. T. Antropologia do ciborgue: as vertigens do pós-humano. Belo Horizonte: Autêntica. 2000.

KELLNER, D. Lendo imagens criticamente: em direção a uma pedagogia pós-moderna. In: SILVA, T. T. Alienigenas na sala de aula. Rio de Janeiro: Vozes. 1995.

LARROSA, J. Tecnologias do eu e Educação. In: SILVA, T. T. (org.) O sujeito da educaşão: estudos foucaultianos. $5^{\text {a }}$ ed. Rio de Janeiro: Vozes. 1994.

LOURO, G. L. Pedagogias da sexualidade. In: LOURO, G. L (org.). O corpo educado: pedagogias da sexualidade. Belo Horizonte: Autêntica. 2000.

LOURO, G. L. Gênero, sexualidade e educação: uma perspectiva pós-estruturalista. Rio de Janeiro: Vozes. 2008.

LOURO, G. L. Gênero e sexualidade: pedagogias contemporâneas. Pro-Posições, v. 19, n. 2, p. 17-23. 2008 a.

MOITA-LOPES, L. P. Identidades fragmentadas: a construção discursiva de raça, gênero e sexualidade em sala de aula. São Paulo: Mercado de Letras, 2002.

PARKER, R. Cultura, economia política e construção social da sexualidade. In: LOURO, G. L (org). O corpo educado: pedagogias da sexualidade. Belo Horizonte: Autêntica. 2000.

SABAT, R. Pedagogia cultural, gênero e sexualidade. Revista Estudos Feministas, Florianópolis, n. 1, p. 12-21, 2001.

SILVA, T. T. Currículo e identidade social: territórios contestados. In: SILVA, T. T. Alienígenas na sala de aula. Rio de Janeiro: Vozes. 1995.

SILVA, T. T. Documentos de identidade: uma introdução às teorias do currículo. Belo Horizonte: Ed. Autêntica. 1999.

SILVA, T. T. (org.). Identidade e diferença: a perspectiva dos estudos culturais. Rio de Janeiro: Vozes. 2000.

WEEKS, J. O Corpo e a Sexualidade. In: LOURO, G. L (org). O corpo educado: pedagogias da sexualidade. Belo Horizonte: Autêntica. 2000.

WILLINSKY, J. Ciência e a origem da raça. In: LOPES, A. C; MACEDO, E. (orgs.). Currículo de ciências em debate. São Paulo: Papirus. 2004.

WOODWARD, K. Identidade e diferença: uma introdução teórica e conceitual. In: SILVA, T. T. (org.). Identidade e diferença: a perspectiva dos estudos culturais. Rio de Janeiro: Vozes. 2000.

Data do Recebimento: 25/09/2012

Data de Aprovação: 20/05/2013

Data da Versão Final: 25/07/2013 